\title{
Preoperative Biliary Drainage in Patients with Obstructive Jaundice: History and Current Status
}

\author{
N. A. van der Gaag • J. J. Kloek • S. M. M. de Castro • \\ O. R. C. Busch • T. M. van Gulik • D. J. Gouma
}

Received: 13 May 2008 / Accepted: 15 July 2008/Published online: 23 August 2008

(C) 2008 The Author(s)

\begin{abstract}
Rationale Preoperative biliary drainage (PBD) has been introduced to improve outcome after surgery in patients suffering from obstructive jaundice due to a potentially resectable proximal or distal bile duct/pancreatic head lesion. In experimental models, PBD is almost exclusively associated with beneficial results: improved liver function and nutritional status; reduction of systemic endotoxemia; cytokine release; and, as a result, an improved immune response. Mortality was significantly reduced in these animal models. Human studies show conflicting results.

Findings For distal obstruction, currently the "best-evidence" available clearly shows that routine PBD does not yield the appreciated improvement in postoperative morbidity and mortality in patients undergoing resection. Moreover, PBD harbors its own complications. However, most of the available data are outdated or suffer from methodological deficits.

Conclusion The highest level of evidence for PBD to be performed in proximal obstruction, as well as over the preferred mode, is lacking but, nevertheless, assimilated in the treatment algorithm for many centers. Logistics and waiting lists, although sometimes inevitable, could be factors that might influence the decision to opt for PBD, as well as an extended diagnostic workup with laparoscopy (on indication) or scheduled preoperative chemotherapy.
\end{abstract}

Keywords Obstructive jaundice $\cdot$ Biliary drainage .

Proximal bile duct tumor $\cdot$ Pancreatic head tumor

\section{Obstructive Jaundice}

Malignant disease of the extrahepatic distal (pancreatic head area) or proximal biliary tract is the most prevalent cause of obstructive jaundice, clinically evident by jaundiced skin, nausea, pruritus, dark urine and discoloration of stool, and the first presenting symptom in up to $90 \%$ of the patients. The hazardous consequence of prolonged and progressive obstructive jaundice is hepatic dysfunction due to bile stasis and cholangitis, eventually leading to hepatic failure.

N. A. van der Gaag $(\varangle) \cdot$ J. J. Kloek $\cdot$ S. M. M. de Castro

O. R. C. Busch • T. M. van Gulik • D. J. Gouma

Department of Surgery,

Academic Medical Center at the University of Amsterdam,

Meibergdreef 9,

1105 AZ Amsterdam, the Netherlands

e-mail: D.J.Gouma@amc.uva.nl
In western countries, pancreatic cancer currently is the fourth cancer type for death, with an incidence of 10-15 per 100,000 , whereas the reported incidence of extrahepatic cholangiocarcinoma (CCA) is approximately 1 per $100,000 .{ }^{1}$ Radical resection of the tumor is the only possible treatment for cure. Pancreatic head tumors and distal CCA are managed by pancreatoduodenectomy (PD), while for proximal or hilar (Klatskin) extrahepatic CCA affecting the CBD, hilar resection with partial hepatectomy is indicated. Unfortunately, locoregional irresectability and/or metastatic disease, which may become apparent during preoperative work-up, preclude resection in the majority of patients.

Although the postoperative mortality after extensive hepatopancreatobiliary surgery has decreased from $20 \%$ to less than $5 \%$ in experienced centers, the overall morbidity remains high at approximately $40-60 \%$, depending on applied definitions. ${ }^{2-6}$ Frequently encountered surgical complications are anastomotic leakage, in particular, pancreaticojejunostomy leakage, hemorrhage, delayed gastric emptying, and impaired wound healing. Nowadays, complications are generally managed nonoperatively, mainly 
due to an emerging role of the interventional radiologist. ${ }^{7}$ Nonsurgical complications consist primarily of sepsis, pneumonia, and renal disorders.

Already in 1935, this increased risk of surgery in jaundiced patients was acknowledged by A.O. Whipple, and he was the first to introduce the concept of preoperative biliary drainage (PBD) by performing a staged PD: application of a cholecystogastrostomy to reduce jaundice was followed by resection at a later stage, depending on the severity of jaundice. ${ }^{8}$ In the mid 1960s, a nonoperative, external drainage procedure was devised: percutaneous transhepatic cholangiography (PTC) was performed using the CIBA needle. ${ }^{9}$ Internal drainage came up in the seventies when the concept of endoscopic retrograde cholangiopancreatography (ERCP) was introduced. In one procedure, a diagnostic investigation was combined with a therapeutic intervention by inserting an endoprosthesis. Up to now, most patients with distal obstruction (pancreatic head/distal bile duct) are treated with ERCP, whereas in patients with proximal biliary obstruction, PTC is generally the preferred method.

The present article will focus on the role of PBD to reduce septic complications following surgery for distal and proximal biliary obstruction by considering the best evidence available in literature.

\section{Experimental Studies}

\section{Obstructive Jaundice}

Obstructive jaundice is associated with a proinflammatory state, resulting from portal and systemic endotoxemia, and experimental studies have extensively reported on the processes that are implicated in the underlying pathophysiological mechanisms; the most elucidated are discussed hereafter. $^{10-12}$

The endotoxin concentration in the portal circulation is increased, as a result of lack of bile salts in the gut lumen with, consequently, an unbalanced bacterial intestinal microflora and increased permeability of the intestinal mucosal barrier, promoting translocation of bacteria. ${ }^{13,14}$ Inadequate clearance of endotoxins in obstructive jaundice has been attributed to an altered reticuloendothelial system (RES) function of Kuppfer cells in the liver. ${ }^{14,15}$ Recently, it has been demonstrated that, in isolated liver Kuppfer cells from cholestatic mice, increased numbers of viable intracellular bacteria after infection were present, suggesting an impaired intracellular bacterial killing. ${ }^{16}$ The exact consequence with respect to development of infectious complications remains to be elucidated.

The exposure to endotoxemia and bacterial translocation due to obstructive jaundice leads to an uncontrolled induction of the inflammatory cascade: animal experiments have shown increased concentrations of proinflammatory cytokines, such as tumor necrosis factor (TNF), IL-6, GRO/ KC (IL-8), and IL-10. ${ }^{17-22}$ Increased concentrations of $\mathrm{TNF}$, mainly produced by liver Kuppfer cells, or rather, the imbalance with its soluble receptors, as antagonists and released from the cell membrane by endotoxemia, are suggested to contribute to development of complications. ${ }^{18,23}$ After endotoxin administration to cholestatic rats, Kennedy et al. demonstrated that blockade of Kuppfer cells with gadolinium chloride leads to a lower systemic TNF activity and subsequently resulted in an improved survival. ${ }^{17}$ On the other hand, the enhanced IL-6 release, as found in jaundiced mice exposed to endotoxin, might actually play an important role in protecting the cholestatic host against hypersensitivity to endotoxin and was found to abrogate cholestatic liver injury. ${ }^{22,24}$ In the perspective of these results found in animal models of biliary obstruction, it appears that the generalized inflammatory state in patients with obstructive jaundice was profoundly different. ${ }^{25}$ Although obstructive jaundice caused alterations in circulating concentrations of endotoxin-binding proteins, neutrophil activation and increased concentrations of IL- 8 , the concentrations of many of the investigated mediators in animals, such as TNF and its receptors, were not as high in patients. ${ }^{25}$ Although biliary drainage did reduce IL-8 and endotoxin binding proteins, it did not change many of the mediators suggested to correlate with mortality in animal experiments.

It was demonstrated that cellular immunity, measured by the lymphocyte response to mitogens (concanavalin-A and phytohemagglutinin), was significantly lower in bile duct ligated rats but did not occur in jaundiced germ-free rats. ${ }^{26}$ This would imply that hyperbilirubinemia itself does not contribute to immunosuppression, but rather, increased levels of gut-derived endotoxins due to obstructive jaundice are responsible because bilirubin levels in both conventional and germ-free bile duct ligated rats were not different. Obstructive jaundice also leads to deeply suppressed natural killer (NK) activity of nonparenchymal liver cells in rats, which can be reversed by biliary drainage of an adequate duration. ${ }^{27,28}$ Furthermore, the decrease in NK cell activity resulted in an enhanced growth of liver metastases, and supposedly, PBD might help to prevent liver metastases after surgery. ${ }^{27}$

Next to an increased risk for development of infectious complications, obstructive jaundice has been associated with renal dysfunction, with its extent depending on the intensity of biliary obstruction. ${ }^{10,29,30}$ In the pathogenesis of renal failure, extracellular volume depletion may be an important factor, and while the observed increases in plasma renin and aldosterone are logical endocrine responses to a reduced extracellular water compartment, there also is a paradoxical rise in plasma atrial natriuretic 
peptide (ANP) in response to biliary obstruction. ${ }^{31}$ The raised plasma ANP level might be the result of the passage of bile components to the blood and is reversed to basal levels after biliary drainage, thereby improving renal dysfunction. ${ }^{31,32}$ Furthermore, myocardial dysfunction in obstructive jaundice has been suggested to be the consequence of hemodynamic disturbances due to altering ANP concentrations, while after biliary drainage, a correlation was found between decreasing ANP concentrations and increasing cardiac output. ${ }^{33}$

\section{Biliary Drainage}

Biliary drainage as a therapeutic method to reduce postoperative septic complications has been shown in multiple experimental models to improve liver function, nutritional status, and cell-mediated immune function; to reduce systemic endotoxemia and cytokine release; and, subsequently, to improve overall immune response. ${ }^{20,26,34-38}$ Mortality was significantly reduced in these animal models. With respect to the preferred route of drainage, internal PBD was found to be superior to external PBD in terms of reduction in endotoxemia and mortality by some, whereas others demonstrated external drainage, although in the shortterm, to lead to a better recovery of cellular immunity than internal drainage. ${ }^{34,39,40}$ In jaundiced rats undergoing hepatectomy, both external and internal PBD improved serum liver function tests; however, a better liver regeneration and function after hepatectomy was observed after internal drainage. $^{41}$

A negative side-effect of biliary drainage is the associated complications of the procedure itself. In dogs, insertion of biliary endoprostheses resulted in bile contamination and severe chronic inflammation of the bile duct. ${ }^{42}$ This inflammatory process led to considerable thickening of the wall in both normal and obstructed bile duct, with transmural, fibrosing inflammation and, occasionally, ulceration. Two months after removal of the endoprosthesis, bacterobilia persisted and the bile duct remained inflamed and dilated, albeit less severe. To put an endoprosthesis in the bile duct before surgery resulted in higher postoperative infectious complications, an increased risk of anastomotic dehiscence, more frequent leakage of infected bile, and increased abscess formation. It is likely that the infected bile and the condition of the bile duct wall, as a consequence of the preoperative stenting, were responsible for these complications.

Concerning the duration of PBD, it has been suggested that adequate recovery of hepatic function depends on the duration of biliary decompression and duration of obstructive jaundice before decompression. ${ }^{43}$ A minimum of 4 6 weeks of preoperative drainage was advised, with even longer periods proposed for patients with a prolonged biliary obstruction before decompression. A more recent study showed that preoperative decompression is necessary for at least 3 weeks before coagulation and hepatic and RES function start improving. ${ }^{44}$

\section{PBD for Distal Obstruction}

Patients suspected to have a tumor in the pancreatic head area (pancreas, distal bile duct, papilla of Vater), without radiological evidence of irresectability, will undergo an exploration with the intention of resection of the tumor. In the preoperative course, a majority of these patients suffer from symptomatic obstructive jaundice.

For many decades, diagnostic strategies comprised the performance of an ERCP in patients with obstructive jaundice, accompanied in most cases with stent placement for PBD as a therapeutic measure for relief of symptoms. Nowadays, stateof-the-art radiological techniques offer a higher diagnostic accuracy than ERCP, require a minimum amount of time, are noninvasive, and have the advantage of assessing local tumor extension, as well as distant metastases. ${ }^{45-47}$ Therefore, ERCP as a diagnostic tool is considered obsolete in many countries, although geographical differences do exist. Implementation of a strategy without diagnostic ERCP is not generally adapted yet in The Netherlands; a survey revealed that, prior to referral for further assessment and (surgical) treatment at the tertiary center, almost $40 \%$ of patients already had ERCP performed, primarily as a diagnostic procedure. $^{48}$

The therapeutic effect of PBD, either by means of ERCP or PTC, has been extensively debated throughout the past few decades. One of the largest prospective randomized trials performed in the USA by Pitt et al. concluded that PBD does not reduce operative risk; however, it increases hospital cost and, therefore, should not be performed routinely. ${ }^{49}$ A systematic review from our institution summarized all retrospective and prospective studies, published between 1966 and 2001, with the aim to evaluate the efficacy of drainage in jaundiced patients, compared to patients that underwent direct surgical treatment. ${ }^{50}$ Outcome measures of the meta-analysis were in-hospital death rate, overall complications resulting from the treatment modality (PBD- and surgery-related complications), and hospital stay. Five randomized controlled studies comprising 302 patients (level I evidence) and 18 cohort studies comprising 2,853 patients (level II evidence) met inclusion criteria and were analyzed. Meta-analysis for both level I and level II studies showed no difference in mortality between patients who had PBD and those who had surgery without PBD. However, overall complication rate was significantly adversely affected by PBD compared with surgery without PBD; for level I, they were $57 \%$ and $42 \%$, 
respectively, indicating a relative risk reduction of $15 \%$ and an absolute risk reduction of $27 \%$ in case surgery would be performed without PBD. Analysis of level II studies showed equal numbers. If PBD had been without complications, the complication rate would be in favor of PBD based on level I studies, and without difference based on level II studies. Further, overall hospital stay was prolonged after PBD. In all it, was concluded that the potential benefit of PBD, in terms of postoperative rates of death and complications, does not outweigh the disadvantage of the drainage procedure and therefore should not be performed routinely, unless further improved PBD techniques would become available.

The inverse relationship between the institutional volume of major oncological surgery and the resulting morbidity and mortality rates is well recognized and the key reason for a plea for centralization of complex surgical procedures. ${ }^{4,51}$ Pisters et al. brought this argument up to justify PBD to create time for referral of patients to highvolume tertiary surgical centers, their (retrospective) study did not demonstrate an increase in the risk of major postoperative complications associated with PBD and stent placement. ${ }^{52,53}$ Logistics in terms of (local) referral patterns, waiting lists, extended diagnostic workup with laparoscopy (on indication), or scheduled preoperative chemotherapy could be other plausible factors that might influence the decision to opt for PBD. Possibly, these factors are region-specific for, at least in the USA, in the eastern part of the country, early surgery without drainage is strongly advocated, whereas in the southern part, PBD is favored. ${ }^{53}$ However, ideally, such logistic arguments should never be decisive in treatment consideration. Furthermore, even in high case-load centers, a hospital volume-outcome effect for ERCP and stenting exists, which should be taken into account in the discussion of whether or not to start with ERCP and drainage before referral. ${ }^{54,55}$

It should be mentioned that the prospective studies included in our meta-analysis largely consisted of a suboptimal design, while they were not carried out according to the basic principles of clinical trial reporting (the CONSORT statement). ${ }^{56}$ Various (outdated) forms of internal and external drainage procedures for both proximal and distal obstruction were included, different durations of drainage were used, and different surgical procedures were followed. These possible methodological and reporting deficiencies might hamper drawing conclusions. Furthermore, due to the time span of included studies, outmoded PBD techniques and materials inevitably add significantly to the negative outcome of drainage.

Therefore, we have conceived a large randomized controlled multicenter trial (in patients needing a PD, distal obstruction) to obtain the highest level of evidence by comparing a "PBD strategy" (standard strategy) with that of an "early-surgery" strategy: the drainage vs. operation (DROP) trial. ${ }^{57}$ Primary outcome measure is the incidence of overall severe complications; secondary outcome measure includes hospital stay, number of invasive diagnostic tests, costs, and quality of life.

\section{PBD for Proximal Obstruction}

Hilar CCA remains one of the most difficult tumors in terms of staging and radical treatment. ${ }^{58}$ Furthermore, the correct mode of preoperative management is still under debate. $^{59,60}$ Most patients with hilar CCA show liver dysfunction caused by obstructive jaundice, which has proven to be a significant risk factor in major liver resection. ${ }^{61-63}$

As mentioned earlier, animal studies concerning PBD are convincing in terms of complication reduction; clinical studies report conflicting results. ${ }^{64-67}$ Two randomized controlled trials, in which a PBD strategy was compared to early-surgery strategy in jaundiced patients, including patients with proximal lesions, did not display a difference in perioperative mortality; however, they encountered a high rate of PBD-procedure-related complications. ${ }^{68,69}$ Cautious interpretation is warranted as these studies used outdated techniques; included a variety of causes of biliary obstruction; and, moreover, comprised only a limited number of patients with proximal CCA. A prospective cohort study found a significantly higher rate of infectious complications if PBD was applied, whereas another study concluded that routine use of PBD was not justified since mortality was not significantly different and recovery of hepatic synthetic function was identical to that of nonjaundiced patients. ${ }^{70,71}$

In contrast, Japanese literature is unanimous in advising and emphasizing the benefit of PBD. ${ }^{72-74}$ The postoperative mortality rates after major liver resections performed for hilar CCA in Japan are low, currently between $0 \%$ and $9 \%$, for which many consider PBD to be an essential element in preoperative management. ${ }^{73-76}$ Most centers agree that, for tumors requiring extensive liver resection, biliary drainage of at least the future remnant liver is necessary to prevent hepatic failure. ${ }^{77}$ With the introduction of preoperative portal embolization, to induce hypertrophy of the future remnant liver, the application of wider resection margins and the development of new endoscopic techniques are other factors that have led to a favorable attitude for a preoperative drainage strategy. ${ }^{78}$

The technique of PBD for proximal obstruction, as well as which part of the liver should be drained, is an ongoing controversy. External drainage by PTC is traditionally the preferred method for relief of obstructive jaundice due to proximal obstruction. Endoscopic biliary drainage, al- 
though a less invasive technique, carries the increased risk of developing cholangitis due to bacterial contamination from the duodenum. ${ }^{78}$ Moreover, endoscopic biliary drainage implicates total biliary drainage (TBD) (entire liver), or at best, hemihepatic drainage by left or right hepatic duct drainage, whereas drainage via PTC offers the possibility to perform more selectively segmental drainage. An argument for selective biliary drainage (SBD) is the subsequent induction of hypertrophy of the future remnant liver and atrophy of the future resected part of the liver. ${ }^{79,80} \mathrm{~A}$ retrospective cohort study investigated 42 consecutive patients who underwent SBD or TBD before hepatectomy. ${ }^{81}$ SBD was found not to increase the risk for cholangitis, compared with TBD. In association with portal vein embolization, SBD was superior to TBD in promoting hypertrophy of the future remnant liver, whereby extended hemihepatectomy could be performed more safely. Although not in the perspective of PBD, the only existing prospective randomized controlled trial comparing TBD vs. SBD appointed patients with unresectable hilar bile duct tumors to undergo either unilateral or bilateral endoscopic hepatic duct drainage. ${ }^{82}$ Unilateral drainage resulted in a higher technical success rate of stent insertion and a significantly lower incidence of complications, mainly early cholangitis.

In spite of the presumed advantages of PTC drainage over endoscopic drainage, it should be noted that no clinical randomized controlled trials exist regarding the most optimal route of drainage in terms of complication reduction and patient burden. Currently, the preferred technique of biliary drainage prior to surgery for a proximal bile duct tumor depends mainly on local expertise.

\section{Summary and Conclusion}

Obstructive jaundice is the most prevalent symptom in potentially resectable distal and proximal lesions of the extrahepatic biliary tract/pancreatic head area. The presence of toxic substances such as bilirubin and bile salts, impaired liver function, and altered nutritional status due to obstructive jaundice have been characterized as factors for the development of complications. Whereas PBD was to yield beneficial effects in experimental models, conflicting results have been observed in human studies. For distal obstruction, currently, the "best evidence" available clearly shows that PBD should not be performed routinely. Unfortunately, most of the available data are outdated, and hopefully, the large prospective randomized controlled DROP trial will solve the dilemma of whether or not $\mathrm{PBD}$, as an additional procedure, improves surgical outcome to such an extent that postponement to resection of progressive malignant disease is justified. ${ }^{57}$ The highest level of evidence for PBD to be performed in proximal obstruction, as well as over the preferred mode, is lacking but, nevertheless, assimilated in the preferred treatment algorithm for many centers. Logistics pose an undesirable, although sometimes inevitable, argument to perform PBD.

Open Access This article is distributed under the terms of the Creative Commons Attribution Noncommercial License which permits any noncommercial use, distribution, and reproduction in any medium, provided the original author(s) and source are credited.

\section{References}

1. Jemal A, Siegel R, Ward E et al. Cancer statistics, 2006. CA Cancer J Clin 2006;56:106-130.

2. Wente MN, Bassi C, Dervenis C et al. Delayed gastric emptying (DGE) after pancreatic surgery: A suggested definition by the International Study Group of Pancreatic Surgery (ISGPS). Surgery 2007;142:761-768. doi:10.1016/j.surg.2007.05.005.

3. Wente MN, Veit JA, Bassi C et al. Postpancreatectomy hemorrhage (PPH): an International Study Group of Pancreatic Surgery (ISGPS) definition. Surgery 2007;142:20-25. doi:10.1016/j. surg.2007.02.001.

4. Gouma DJ, van Geenen RC, van Gulik TM et al. Rates of complications and death after pancreaticoduodenectomy: risk factors and the impact of hospital volume. Ann Surg 2000;232:786-795. doi:10.1097/00000658-200012000-00007.

5. Bassi C, Dervenis C, Butturini G et al. Postoperative pancreatic fistula: an international study group (ISGPF) definition. Surgery 2005;138:8-13. doi:10.1016/j.surg.2005.05.001.

6. Dindo D, Demartines N, Clavien PA. Classification of surgical complications: a new proposal with evaluation in a cohort of 6336 patients and results of a survey. Ann Surg 2004;240:205-213. doi:10.1097/01.sla.0000133083.54934.ae.

7. Sohn TA, Yeo CJ, Cameron JL et al. Pancreaticoduodenectomy: role of interventional radiologists in managing patients and complications. J Gastrointest Surg 2003;7:209-219. doi:10.1016/ S1091-255X(02)00193-2.

8. Whipple AO, Parsons WB, Mullins CR. Treatment of carcinoma of the ampulla of Vater. Ann Surg 1935;102:763-779. doi:10.1097/00000658-193510000-00023.

9. Glenn F, Evans JA, Mujahed Z, Thorbjarnsarson B. Percutaneous transhepatic cholangiography. Ann Surg 1962;156:451-462. doi:10.1097/00000658-196209000-00012.

10. Greve JW, Gouma DJ, Buurman WA. Complications in obstructive jaundice: role of endotoxins. Scand J Gastroenterol Suppl 1992;194:8-12. doi:10.3109/00365529209096019.

11. Clements WD, Erwin P, McCaigue MD et al. Conclusive evidence of endotoxaemia in biliary obstruction. Gut 1998;42:293-299.

12. Kimmings AN, Van Deventer SJ, Obertop H et al. Inflammatory and immunologic effects of obstructive jaundice: pathogenesis and treatment. J Am Coll Surg 1995;181:567-581.

13. Parks RW, Clements WD, Smye MG et al. Intestinal barrier dysfunction in clinical and experimental obstructive jaundice and its reversal by internal biliary drainage. Br J Surg 1996;83:13451349. doi:10.1002/bjs. 1800831007.

14. Clements WD, McCaigue M, Erwin P et al. Biliary decompression promotes Kupffer cell recovery in obstructive jaundice. Gut 1996;38:925-931. doi:10.1136/gut.38.6.925.

15. Tanaka N, Ryden S, Bergqvist L et al. Reticulo-endothelial function in rats with obstructive jaundice. $\mathrm{Br} \mathrm{J}$ Surg 1985;72:946-949. doi:10.1002/bjs.1800721204. 
16. Minter RM, Fan MH, Sun J et al. Altered Kupffer cell function in biliary obstruction. Surgery 2005;138:236-245. doi:10.1016/j. surg.2005.04.001.

17. Kennedy JA, Clements WD, Kirk SJ et al. Characterization of the Kupffer cell response to exogenous endotoxin in a rodent model of obstructive jaundice. Br J Surg 1999;86:628-633. doi:10.1046/ j.1365-2168.1999.01114.x.

18. Nehez L, Andersson R. Compromise of immune function in obstructive jaundice. Eur J Surg 2002;168:315-328. doi:10.1080/ 11024150260284815.

19. Ohtsuka M, Miyazaki M, Kondo Y, Nakajima N. Neutrophilmediated sinusoidal endothelial cell injury after extensive hepatectomy in cholestatic rats. Hepatology 1997;25:636-641. doi:10.1002/hep.510250324.

20. Bemelmans MH, Gouma DJ, Greve JW, Buurman WA. Cytokines tumor necrosis factor and interleukin-6 in experimental biliary obstruction in mice. Hepatology 1992;15:1132-1136. doi:10.1002/ hep. 1840150626.

21. Abe T, Arai T, Ogawa A et al. Kupffer cell-derived interleukin 10 is responsible for impaired bacterial clearance in bile duct-ligated mice. Hepatology 2004;40:414-423. doi:10.1002/hep.20301.

22. Sewnath ME, van der PT, van Noorden CJ et al. Cholestatic interleukin-6-deficient mice succumb to endotoxin-induced liver injury and pulmonary inflammation. Am J Respir Crit Care Med 2004;169:413-420. doi:10.1164/rccm.200303-311OC.

23. Bemelmans MH, Greve JW, Gouma DJ, Buurman WA. Increased concentrations of tumour necrosis factor (TNF) and soluble TNF receptors in biliary obstruction in mice; soluble TNF receptors as prognostic factors for mortality. Gut 1996;38:447-453. doi:10.1136/ gut.38.3.447.

24. Gehring S, Dickson EM, San Martin ME et al. Kupffer cells abrogate cholestatic liver injury in mice. Gastroenterology 2006;130:810-822. doi:10.1053/j.gastro.2005.11.015.

25. Kimmings AN, Van Deventer SJ, Obertop H et al. Endotoxin, cytokines, and endotoxin binding proteins in obstructive jaundice and after preoperative biliary drainage. Gut 2000;46:725-731. doi:10.1136/gut.46.5.725.

26. Greve JW, Gouma DJ, Soeters PB, Buurman WA. Suppression of cellular immunity in obstructive jaundice is caused by endotoxins: a study with germ-free rats. Gastroenterology 1990;98:478-485.

27. Hirazawa K, Hazama S, Oka M. Depressed cytotoxic activity of hepatic nonparenchymal cells in rats with obstructive jaundice. Surgery 1999;126:900-907.

28. Lane DR, Joshi P, Grogan JB et al. Suppression of natural killer cell activity in biliary obstruction. Am Surg 1996;62:259-262.

29. Wait RB, Kahng KU. Renal failure complicating obstructive jaundice. Am J Surg 1989;157:256-263. doi:10.1016/0002-9610 (89)90540-0.

30. Padillo FJ, Cruz A, Briceno J et al. Multivariate analysis of factors associated with renal dysfunction in patients with obstructive jaundice. Br J Surg 2005;92:1388-1392. doi:10.1002/bjs.5091.

31. Martinez-Rodenas F, Pereira JA, Jimenez W et al. Circulating bile is the main factor responsible for atrial natriuretic peptide release in experimental obstructive jaundice. Br J Surg 1998;85:480-484. doi:10.1046/j.1365-2168.1998.00661.x.

32. Padillo FJ, Briceno J, Cruz A et al. Randomized clinical trial of the effect of intravenous fluid administration on hormonal and renal dysfunction in patients with obstructive jaundice undergoing endoscopic drainage. Br J Surg 2005;92:39-43. doi:10.1002/bjs.4790.

33. Padillo J, Puente J, Gomez M et al. Improved cardiac function in patients with obstructive jaundice after internal biliary drainage: hemodynamic and hormonal assessment. Ann Surg 2001;234:652-656. doi:10.1097/00000658-200111000-00010.

34. Gouma DJ, Coelho JC, Fisher JD et al. Endotoxemia after relief of biliary obstruction by internal and external drainage in rats. Am J Surg 1986;151:476-479. doi:10.1016/0002-9610(86)90107-8.
35. Roughneen PT, Gouma DJ, Kulkarni AD et al. Impaired specific cell-mediated immunity in experimental biliary obstruction and its reversibility by internal biliary drainage. J Surg Res 1986;41:113125. doi:10.1016/0022-4804(86)90016-8.

36. Gouma DJ, Roughneen PT, Kumar S et al. Changes in nutritional status associated with obstructive jaundice and biliary drainage in rats. Am J Clin Nutr 1986;44:362-369.

37. Bemelmans MH, Gouma DJ, Greve JW, Buurman WA. Effect of antitumour necrosis factor treatment on circulating tumour necrosis factor levels and mortality after surgery in jaundiced mice. Br J Surg 1993;80:1055-1058. doi:10.1002/bjs.1800800845.

38. Megison SM, Dunn CW, Horton JW, Chao H. Effects of relief of biliary obstruction on mononuclear phagocyte system function and cell mediated immunity. Br J Surg 1991;78:568-571. doi:10.1002/bjs. 1800780516.

39. Gouma DJ, Coelho JC, Schlegel JF et al. The effect of preoperative internal and external biliary drainage on mortality of jaundiced rats. Arch Surg 1987;122:731-734.

40. Mizuguchi K, Ajiki T, Onoyama H et al. Short-term effects of external and internal biliary drainage on liver and cellular immunity in experimental obstructive jaundice. J Hepatobiliary Pancreat Surg 2004;11:176-180. doi:10.1007/s00534-003-0886-z.

41. Saiki S, Chijiiwa K, Komura M et al. Preoperative internal biliary drainage is superior to external biliary drainage in liver regeneration and function after hepatectomy in obstructive jaundiced rats. Ann Surg 1999;230:655-662. doi:10.1097/00000658-199911000-00007.

42. Karsten TM, Davids PH, van Gulik TM et al. Effects of biliary endoprostheses on the extrahepatic bile ducts in relation to subsequent operation of the biliary tract. J Am Coll Surg 1994;178:343-352.

43. Koyama K, Takagi Y, Ito K, Sato T. Experimental and clinical studies on the effect of biliary drainage in obstructive jaundice. Am J Surg 1981;142:293-299. doi:10.1016/0002-9610(81)90296-8.

44. Kawarada Y, Higashiguchi T, Yokoi H et al. Preoperative biliary drainage in obstructive jaundice. Hepatogastroenterology 1995;42:300-307.

45. Johnson CD. Guidelines for the management of patients with pancreatic cancer periampullary and ampullary carcinomas. Gut 2005;54(Suppl 5):v1-16. doi:10.1136/gut.2004.057059.

46. de Groen PC, Gores GJ, LaRusso NF et al. Biliary tract cancers. N Engl J Med 1999;341:1368-1378. doi:10.1056/NEJM1999 10283411807.

47. Phoa SS, Reeders JW, Rauws EA et al. Spiral computed tomography for preoperative staging of potentially resectable carcinoma of the pancreatic head. Br J Surg 1999;86:789-794. doi:10.1046/j.1365-2168.1999.01138.x.

48. Tilleman EH, Benraadt J, Bossuyt PM et al. Diagnosis and treatment of pancreatic carcinoma in the region of Amsterdam Comprehensive Cancer Care Center in 1997. Ned Tijdschr Geneeskd 2001;145:1358-1362.

49. Pitt HA, Gomes AS, Lois JF et al. Does preoperative percutaneous biliary drainage reduce operative risk or increase hospital cost? Ann Surg 1985;201:545-553. doi:10.1097/00000658-198505000-00002.

50. Sewnath ME, Karsten TM, Prins MH et al. A meta-analysis on the efficacy of preoperative biliary drainage for tumors causing obstructive jaundice. Ann Surg 2002;236:17-27. doi:10.1097/ 00000658-200207000-00005.

51. van Heek NT, Kuhlmann KF, Scholten RJ et al. Hospital volume and mortality after pancreatic resection: a systematic review and an evaluation of intervention in the Netherlands. Ann Surg 2005;242:781-788. discussion doi:10.1097/01.sla.0000188462. 00249.36 .

52. Pisters PW, Hudec WA, Hess KR et al. Effect of preoperative biliary decompression on pancreaticoduodenectomy-associated morbidity in 300 consecutive patients. Ann Surg 2001;234:4755. doi:10.1097/00000658-200107000-00008. 
53. Pisters PW, Lee JE, Vauthey JN, Evans DB. Comment and perspective on Sewnath and colleagues' recent meta-analysis of the efficacy of preoperative biliary drainage for tumors causing obstructive jaundice. Ann Surg 2003;237:594-595. doi:10.1097/ 00000658-200304000-00024.

54. Sewnath ME, Birjmohun RS, Rauws EA et al. The effect of preoperative biliary drainage on postoperative complications after pancreaticoduodenectomy. J Am Coll Surg 2001;192:726-734. doi:10.1016/S1072-7515(01)00819-5.

55. Isenberg G, Gouma DJ, Pisters PW. The on-going debate about perioperative biliary drainage in jaundiced patients undergoing pancreaticoduodenectomy. Gastrointest Endosc 2002;56:310-315.

56. Moher D, Jones A, Lepage L. Use of the CONSORT statement and quality of reports of randomized trials: a comparative beforeand-after evaluation. JAMA 2001;285:1992-1995. doi:10.1001/ jama.285.15.1992.

57. van der Gaag NA, de Castro SM, Rauws EA et al. Preoperative biliary drainage for periampullary tumors causing obstructive jaundice; DRainage vs. (direct) OPeration (DROP-trial). BMC Surg 2007;7:3. doi:10.1186/1471-2482-7-3.

58. Lazaridis KN, Gores GJ. Cholangiocarcinoma. Gastroenterology 2005;128:1655-1667. doi:10.1053/j.gastro.2005.03.040.

59. Clavien PA, Emond J, Vauthey JN et al. Protection of the liver during hepatic surgery. J Gastrointest Surg 2004;8:313-327. doi:10.1016/j.gassur.2003.12.006.

60. Clavien PA, Petrowsky H, DeOliveira ML, Graf R. Strategies for safer liver surgery and partial liver transplantation. N Engl J Med 2007;356:1545-1559. doi:10.1056/NEJMra065156.

61. Blamey SL, Fearon KC, Gilmour WH et al. Prediction of risk in biliary surgery. Br J Surg 1983;70:535-538. doi:10.1002/ bjs. 1800700910 .

62. Dixon JM, Armstrong CP, Duffy SW, Davies GC. Factors affecting morbidity and mortality after surgery for obstructive jaundice: a review of 373 patients. Gut 1983;24:845-852. doi:10.1136/gut.24.9.845.

63. Shigeta $H$, Nagino $M$, Kamiya $J$ et al. Bacteremia after hepatectomy: an analysis of a single-center, 10-year experience with 407 patients. Langenbecks Arch Surg 2002;387:117-124. doi:10.1007/s00423-002-0301-2.

64. Suzuki H, Iyomasa S, Nimura Y, Yoshida S. Internal biliary drainage, unlike external drainage, does not suppress the regeneration of cholestatic rat liver after partial hepatectomy. Hepatology 1994;20:1318-1322.

65. Aronson DC, Chamuleau RA, Frederiks WM et al. The effect of extrahepatic cholestasis on liver regeneration after partial hepatectomy in the rat. Liver 1995;15:242-246.

66. Ohtsuka M, Miyazaki M, Kondo Y, Nakajima N. Neutrophilmediated sinusoidal endothelial cell injury after extensive hepatectomy in cholestatic rats. Hepatology 1997;25:636-641. doi:10.1002/hep.510250324.

67. Saiki S, Chijiiwa K, Komura M et al. Preoperative internal biliary drainage is superior to external biliary drainage in liver regeneration and function after hepatectomy in obstructive jaundiced rats. Ann Surg 1999;230:655-662. doi:10.1097/00000658-199911000-00007.

68. Hatfield AR, Tobias R, Terblanche J et al. Preoperative external biliary drainage in obstructive jaundice. A prospective controlled clinical trial. Lancet 1982;2:896-899. doi:10.1016/S0140-6736 (82)90866-2.

69. McPherson GA, Benjamin IS, Hodgson HJ et al. Pre-operative percutaneous transhepatic biliary drainage: the results of a controlled trial. Br J Surg 1984;71:371-375. doi:10.1002/ bjs. 1800710522 .

70. Hochwald SN, Burke EC, Jarnagin WR et al. Association of preoperative biliary stenting with increased postoperative infectious complications in proximal cholangiocarcinoma. Arch Surg 1999;134:261-266. doi:10.1001/archsurg.134.3.261.

71. Cherqui D, Benoist S, Malassagne B et al. Major liver resection for carcinoma in jaundiced patients without preoperative biliary drainage. Arch Surg 2000;135:302-308. doi:10.1001/archsurg. 135.3.302.

72. Nimura Y, Kamiya J, Kondo $\mathrm{S}$ et al. Aggressive preoperative management and extended surgery for hilar cholangiocarcinoma: Nagoya experience. J Hepatobiliary Pancreat Surg 2000;7:155162. doi: $10.1007 / \mathrm{s} 005340050170$.

73. Seyama Y, Kubota K, Sano K et al. Long-term outcome of extended hemihepatectomy for hilar bile duct cancer with no mortality and high survival rate. Ann Surg 2003;238:73-83. doi:10.1097/00000658-200307000-00010.

74. Kawasaki S, Imamura H, Kobayashi A et al. Results of surgical resection for patients with hilar bile duct cancer: application of extended hepatectomy after biliary drainage and hemihepatic portal vein embolization. Ann Surg 2003;238:84-92. doi:10.1097/00000658-200307000-00011.

75. Kosuge T, Yamamoto J, Shimada $\mathrm{K}$ et al. Improved surgical results for hilar cholangiocarcinoma with procedures including major hepatic resection. Ann Surg 1999;230:663-671. doi:10.1097/00000658-199911000-00008.

76. Nagino M, Kamiya J, Nishio $\mathrm{H}$ et al. Two hundred forty consecutive portal vein embolizations before extended hepatectomy for biliary cancer: surgical outcome and long-term follow-up. Ann Surg 2006;243:364-372. doi:10.1097/01.sla.0000201482.11876.14.

77. Belghiti J, Ogata S. Preoperative optimization of the liver for resection in patients with hilar cholangiocarcinoma. HPB 2005;7:252-253.

78. Maguchi H, Takahashi K, Katanuma A et al. Preoperative biliary drainage for hilar cholangiocarcinoma. J Hepatobiliary Pancreat Surg 2007;14:441-446. doi:10.1007/s00534-006-1192-3.

79. Miyagawa S, Makuuchi M, Kawasaki S. Outcome of extended right hepatectomy after biliary drainage in hilar bile duct cancer. Arch Surg 1995;130:759-763.

80. Hadjis NS, Adam A, Gibson R et al. Nonoperative approach to hilar cancer determined by the atrophy-hypertrophy complex. Am J Surg 1989;157:395-399. doi:10.1016/0002-9610(89)90583-7.

81. Ishizawa T, Hasegawa K, Sano K et al. Selective versus total biliary drainage for obstructive jaundice caused by a hepatobiliary malignancy. Am J Surg 2007;193:149-154. doi:10.1016/j.amjsurg. 2006.07.015.

82. De Palma GD, Galloro G, Siciliano $\mathrm{S}$ et al. Unilateral versus bilateral endoscopic hepatic duct drainage in patients with malignant hilar biliary obstruction: results of a prospective, randomized, and controlled study. Gastrointest Endosc 2001;53:547-553. doi:10.1067/mge.2001.113381. 